\title{
NASIONALISME RELIGIUS*
}

Intisari Pancasila itu adalah gotong royong. Itulah Filsafat Organisme, yang memandang Semesta Realitas itu sebagai berstruktur (Lahir- Batin) dan berproses (AwalAkhir).

\section{A. Pendahuluan}

Apakah yang terjadi selama ini? Korupsi “Kefilsafatan” Pancasila. Kadar Kefilsafatan Pancasila itu terabaikan, tetapi tanpa disadari; sehingga yang merajalela "kefilsafatan” yang lain, apakah itu Konsumtivisme atau Hedonisme atau bahkan "Filsafat”-Korupsi yang lainnya. yang tidak kalah bahayanya, yakni yang memandang bahwa Pancasila itu bukan suatu Sistem Filsafat. Istilah Filsafat Pancasila itu bisa berkonotasi Philosophy of Pancasila dan PancasilaPhilosophy. Pada yang pertama terbuka berbagai kajian, misalnya IslamicPhilosophy of Pancasila; sementara untuk yang kedua : Pancasila-Philosophy of Islam. Kebulatan sistematisnya tentu saja berupa Pancasila-Philosophy of Pancasila.

Pancasila itu sungguh suatu Filsafat, terbukti dari dapatnya Pancasila itu disarikan sebagai Tri-Sila, (Sosio-Nasionalisme, Sosio-Demokrasi dan Ketuhanan YME), bahkan Eka-Sila, yakni Gotong- royong. Pada skala global, dunia bahkan memiliki Filsafat Gotong- Royong itu, yakni Filsafat Organisme (Filsafat Proses), yang memandang semesta segala itu sebagai berstruktur (Lahir - Batin) dan Berproses (Awal-Akhir). Kearifan lokal .Jawa misalnya mengenal baik struktur

\footnotetext{
*Disampaikan dalam Seminar "Internalsasi Nilai-Nilai Moral Keagamaan dan Kebangsaan ke dalam Mata Kuliah, UNY
} 
Ralitas itu sebagai Ajaran Pamoring Kawula - Gusti, sementara mengenai Proses kosmisnya : Sangkan-Paraning Dunadi.

Sila - sila dalam Pancasila itu mengenai struktur hirarkhis Realitas Sila ke5 itu “lahir”nya; sila ke-I “Batin”-nya. Tidak cukup mengatakan bahwa Pancasila itu lahir”;1-6-1945; Pancasila itu sungguh-sungguh lahir, manakala Keadilan Sosial bagi seluruh rakyat Indonesia sudah terwujud. Yang sungguh-sungguh menjadi masalah adalah pada “prosesnya”-nya. Kenyataan memperlihatkan bahwa terjadi kesalahan urutan bacaan kejadian, yakni bukannya "berakit-rakit ke hulu, berenang-renang ke tepian” (hilirnya), melainkan “Bersenang senang dahulu (“mengkonsumsi hutang”), “Bersusah susah generasi kemudian”.

\section{B. Awal-Akhir, Lahir-Batin}

Anda lahir dari mana? Kalau jawabannya; “Dari rahim Ibu”, maka itu lah jawabannya menurut ilmu Kebidanan, kita “Lahir” dari “Satin”. Maka sungguh penting untuk mengingat pesan Prof. Dr. Mr. Soepomo agar kita tidak melupakan suasana Kebatinan (Geistlichen Hintergrund) di balik seluruh produk hukum. Namun perlu diingat bahwa balk kata "lahir" ataupun "Satin” kedua-duanya adalah bahasa Arab. Maka agar kita tidak berhenti pada having religion melainkan berlanjut ke being religious, harus kita kemukakan kearifan lokal pendukungnya. Lahir itu babar, gelar, gumelar. Kalau demikian maka "Batin” itu gumolong, gumeleng. Mereka yang menempuh laku “Lenging Cipta wus Gumeleng”-lah yang seharusnya ngasta pusaraning adil. Itu memerlukan Ilmu Pengendalian Diri, yakni Cybernetics (Wiener, N., 1966). Dari situ akan nampak jelas urutan skala 
prioritas, ambeg adil paramaarta. Terwujudnya sila ke-5, yang sudah sekian lama digelar namun masih berupa "tikar yang terbentang dan berlubang yang seharusnya ditambal jadah (hablu minannas) dan sajadah (hablu minallah) seharusnya diikuti oleh langkah mempersilahkan tamunya masuk dan duduk, bukannya malah ngurusi jadah yang bau, karenanya memberikannya pada anjing, sementara anjingnya mati, lalu lemparkanlah anjing itu ke kali, karena kalinya banjir maka lemparkanlah bangkai anjing ke pinggir kali.

Mengapa kita salah urutan bacaan kejadian? Muslim yang taat pada pesan Minangkabau perihal Tuah Sakato pasti tahu persis hal itu, bahkan lengkap dengan tata cara koreksiannya terhadap "imam" kehidupan (QS 94). Kesalahan pertama ialah kadar kualitas bacaan yakni yang tidak "melapangkan dada”. Biarkanlah daun itu tetap hijau, namun kenanga tetap kuning dan mawar tetap merah; sebab kalau semuanya priya, lalu adu tongkat; sementara kalau semuanya wanita lalu adu bola.

Hanya mereka yang dilapangkan dadanya, yang diringankan bebannya, dan ditegakkan tulang punggungnya, namun tetap lentur, sehingga ingatannyapun ditindihkan. Mereka yang ditinggikan ingatannyalah yang membaca struktur kejadian secara benar, bahwa ”beserta kesulitan itu kemudahan”. Kelanjutannya adalah program pembangunan (berprestasi ba'da prestasi).

Prof. DR.Drs. Mr. Notonagoro, memperingatkan bahwa sila-sila Pancasila yang hirarkhis piramidal, sesuai dengan struktur Realitas (Taylor, A.E,, 1929) sekaligus mengemukakan tentang analisis ontologis, bahwa segala sesuatu berdasar pada adanya hal-hal yang menjadi pokok isi masing-masing sila, disertai 
dengan konsekuensi aksiologis, bahwa segala perlengkapan negara harus sesuai dengan hakikat abstrak sila-sila Pancasila, ditambah dengan kenyataan bahwa Pemerintah NKRI itu berdiri diatas kesemuanya itu,

Sila ke - 5, kalau terlambat realisasinya sebagai keadilan distributif karena kesalah'n pada sila ke- 4 (keadilan legal) dan sila ke- 3 (keadilan komutatif), malah bisa membalik yakni Rakyat aktif menyelenggarakan pengadilan (Rakyat) bagi para wakilnya, yang kini tengah bermasalah, apalagi kalau diukur berdasarkan Sumpah Rakyat, sehari sebelum lengsernya Pak Harto:

Kami Rakyat Indonesia mengaku bertanah air satu: Tanah air tanpa penindasan Kami Rakyat Indonesia mengaku Berbangsa Satu: Bangsa Yang Gandrung Keadilan

Kami Rakyat Indonesia Mengaku Berbahasa Satu: Bahasa KEBENARAN

\section{Budaya dan Agama}

Pancasila itu mempertemukan Budaya Timur dan Budaya Barat, sekaligus Utara dan Selatan, sambil dengan sangat hati-hati menjaga titik singgungnya dengan Agama, berdasarkan pesan kearifan lokal: Agama Ageming Aji ( M.N.IV, tt). Yang dimaksud dengan Aji disini bukannya sosok Raja, melainkan Ketuhanan Yang Maha Esa. Demikian pula pasal yang mengatakan: sesuai dengan Agama dan Kepercayaannya itu, yang terakhir disitu bukannya mengenai aliran kepercayaan. terhadap Tuhan Yang Maha Esa, melainkan justru Ketuhanan Yang Maha Esa itu sendiri.

Sidang konstituante 1955 mempErlihatkan kesalahan proporsi pemahaman hubungan antara Budaya dan Agama. Tidak ada yang salah dengan Agama 
ditangan Nabi-nabi, sementara Nabi belakangan bukannya mengoreksi kesalahan Nabi sebelumnya, melainkan kesalahan ummat terdahulu dalam memahami ajaran Nabinya, justru karena tidak ada jaminan bahwa kita tidak salah paham atas agama kita.

\section{Stabilitas Struktural}

Menurut DR Ong Kok Ham, Pak Harto bersiap lengser pada 1985, sesuai dengan rotasi historisitas setiap 20 tahun (1905-08, 1925-28, 1945-48, 1965-68, 1985-88) sehingga karena pada tahun 1985 itu Pak Harto tidak jadi lengser, maka UGM mulai dengan program studi baru yakni Polemologi. Salah satu teori yang bergema dalam kajian Polemologi ialah Teori Stabilitas Struktural dari Rene Thorn, bahwa:"bercabang-cabangnya pohon, aliran sungai, urat saraf, dan masalah itu mengikuti pola yang sama. Dalam kaitan ini sungguh mengagumkan sistem percabangan Iman, yang terlengkap yakni bercabang 77, dari pokok Sajaratul Yaqin ("Kesaksian Ontologis") sampai dengan ujungnya yang paling lembut, yakni pupus mupus. Namun menurut Bayanul Iman (Jauhar Tauhid) ujung paling jauh tadi malah "memindah duri dari jalan umum", sebuah acuan perbuatan yang sangat konkrit Istilah kongkret ini perlu dikembalikan kepada akar etimologisnya, yakni concrescence, yang bagi telah manusia tidak lain ialah terpenuhinya ajaran "kasidhan - jati", melainkan karena optimali kepekaan diri sebagai flamen super, serambut pinara sasra, sehingga terang benderangnya sesuai dengan rumus: bilangan berapapun kalau dibagi 0 (nol) hasilnya infinitum. "Duri" yang tanggal, 
yang menghalangi jalan umum (Cahaya Maha Cahaya) ialah konsepsi diri yang salah, yang menjadi aling-aling sehingga orangnya menjadi maling.

'I'atsir Pancasila pada era Orde Baru, sangat menarik kalau dihubungkan dengan era 500 tahun paska Sabda-Palon Noyo Genggong, namun tersisa aneh dilihat dari analisis metodologisnya, lebih-lebih kalau diukur dari pangkal ukuran hal-hal prinsipiil, baik yang umum maupun yang khusus. Filsafat memberikan sumbangan prinsip-prinsip yang self-evident, yang terang dan wijang, yang selama ini kurang mendapat perhatian yang memadai. Bahkan Amandemen yang kini terjadipun tidak luput dari terabaikannya prisip-prisip Khusus Kebenaran, baik mengenai Alasan Secukupnya (Principium Ratio Sufflcienties) ataupun Principium Excemplanis (Asas percontohan atau Ing Ngarsa sung Tuladha)

\section{F. Filsafat Kepemimpinan Dan Etika Kekuasaan}

Ketika Filsafat lahir di Yunani kuno (Ionia), maka Mitologi diganti oleh Penalaran Rasional, yakni tahapan Metafisis-Ontologis, yang selanjutnya melahirkan pendekatan Ilmiah-Fungsional; demikian van Peursen di dalam Strategi Kebudayaannya. Tidak demikian dengan “lahir”-nya Pancasila. Ketika Pancasila "lahir" bahkan sampai kini alam pemikiran bangsa Indonesia masih didominasi oleh tahapan Mitologis. Mengapa? Kemungkinan jawabannya ada dua; pertama di dalam Mitologi kita memang terdapat hal-hal tersembunyi, yang masih perlu diungkap, setidak-tidaknya kandungan maknawi simboliknya, kedua kajian kefilsafatan asas Pancasila justru mengabaikan kadar kefilsafatannya. Filsafat itu apa? Setidak-tidaknya terdapat lima makna didalam istilah Filsafat, 
yakni: 1. Pengantar Hikmah, 2. Sistem Hakikat (mencakup Syariat yang Informatif, Tarekat yang Transformatif, hakikat yang konformatif, serta di atas segala-galanya: Makrifat yang Illuminatif), 3. Sinotik Eksistensial, 4. Pandangan Hidup, dan 5. Induk segala llmu Pengetahuan.

Kelahiran Filsafat di Yunani yang terjadi pada abad 5 SM itu paralel dengan munajadnya Nabi Musa Kalimullah, a.s di bukit Sinai, serta diperolehnya The Ten Commandment, sementara di dunia Tiniur, P. Sidarta mencapai Pencerahan Paripurna dan menjadi seorang Budha. Kini pada abad 21, ketika Dunia telah menjadi kesatuan Modernitas berkat Ilmu dan Tekhnologi dari. Barat, halnya jangan laiu kita lalai, mengingat kajian perihal Fakta, Faktor, Fungsi dan Peran. Yang demikian itu berhubungan dengan makna Kemerdekaan Indonesia. Menurut Yule Fineberg istilah Merdeka itu mengandung makna; 1 Bebas dari halhal negatif untuk menggapai hal-hal positif 2. Pergantian peran dari Objek Penderita ke Subyek Pelaku, 3. Otonomis, 4. Adil (dalam arti Kemerdekaan seseorang/sesuatu fihak, misalnya Bangsa/Negara tidak boleh mengancam fihak lainnya; demikian pula sesuatu aspek kehidupan tidak boleh terlampau dominan terhadap aspek yang lainnya).

Bagaimana mungkin bahwa sesuatu Ilmu (dalam hal ini Filsafat) bisa menjadi Induk segala Ilmu? Karena kandungan Prinsip-prinsip Kebenaran yang self-evident, yang terang dan wijang, clearly dan distinctly, Qur'any dan Furqony. Bidang inilah yang kebanyakan orang justru tidak tahu (bahwa dirinya tidak tahu/apalagi tidak mau tahu). 


\begin{abstract}
Prinsip-prinsip Kebenaran itu mencakup Yang Umum (Principium Identitalis, Principim Contradictionis dan Principium Exclusi Tertii) serta Prinsip-prinsip Khusus (Principim Ratio Sufficientis mencakup 4 hal, serta Principium Exemplaris)
\end{abstract}

\title{
G. Dari Aristokrasi ke Meritokrasi
}

Filsafat Kepemimpinan dan Etika Kekuasaan di Barat bermula dari Aristokrasi, berturut-turut ke Teeokrasi, lalu Demokrasi beserta Teknokrasi untuk pada saatnya kini tengah mulai menguat faham Meritokrasi. Kesemuanya itu tidak bisa dipisahkan dari faktor-faktor penyangganya, terutama tahapan Strategi Kebudayaan, bahkan Kosmologinya tentang Ruang dan Waktu mencakup Ruang Pribadi, Ruang Publik, Ruang Ruhani, bahkan Ruang Tanpa Batas / tak Terbatas, yakni Ruang Ilahi. Yang tarjadi selama ini, termasuk mengenai Dunia Pendidikan orang puas ketika sudah melakukan upaya Foto Kopi, padahal yang dapat difoto kopi hanyalah yang di permukaan.

\section{H. Ketuhauan di balik Kehutanan vs Rimba penuh Riba}

Kalau di dalam hutan dipasang EEG, Electrical Encephalo Graph dan masuklah blandong (illegal loging) maka layar EEG-nya kacau balau, sementara kalau yang masuk itu parker atau tukang kebun yang penuh rasa kasih sayang terhadap aneka ragam hayati, layar EEG-nya alpha rythmik. Jadi hutan itu penuh kepekaan Tahasia Ketuhanan. 
Di sisi lain dunia kini penuh riba, sehingga Pasar Global malah menjadi Rimba penuh Riba. Menurut Bp. Mr. Syafruddin Prawiranegara riba itu bertingkat 3, yakni Riba dalam bidang Ekonomi, yakni Untung atas kerugian fihak lain; riba dalam bidang Pemerintahan, yakni Memerintah atas Penderitaan Rakyat, serta yang paling sulit disadari adalah Riba dalam bidang Ilmu, yakni memperoleh kemudahan temuan ilmu \& teknologi fihak lain, namun justru tidak menggugah kuriositas sebagai pemacu temuan baru; kesemuanya itu akan berakibat indolensia kemampuan kreativitas generasi berikutnya.

\section{I. "Kakang Semar iki Alas apa?}

Itulah pertanyaan klise ki dhalang, memalui Sang Arjuna, ketika tokoh panengah Pandhawa itu turun gunung, setelah gentur dalam olah laku dan ilmu, sehingga ia sah mewakili kualitas kasatriya Pinandhita. Yang menjawab justru Gareng: “Alas projek, nDara!”. Betapa terkejutnya Petruk Kanthong Bolong atas jawaban Nala Gareng tadi, sehingga Petruk pun curiga, jangan-jangan kakaknya mendapatkan projek besar karena dekat dengan orang besar. Garengpun menyanggahnya. "Ora, ki Truk!

Aku wedi wewalere Rama; kalau aku dapat projek dari orang besar, maka kalau Gareng menjadi besar kan namanya GARONG!

\section{J. Orandum est ut suit, "Mens sana in corpore sano”}

Rakyat itu primer; wakil rakyat itu sekunder. Di dalam tubuh yang sehat (dalam segala ranah makna) tidak selalu terdapat jiwa yang sehat. Maka 
lengkapnya peribahasa itu diawali dengan suatu do'a. Biarkanlah Rakyat stabil penuh kepekaan wulu-cumbu. bahkan kalau mungkin "weruh sadurunge winarah”, sehingga faham penuh mengenai laku Arga Dilah, Arga Tiling, karena struktur ke diriannya terbebas dari format ke-Iblis-an, sementara fungsi faalnya terbebas dari gerak menjauhi Yang Ilahi, yakni fungsi syetan. 